\title{
Doxycycline and Benznidazole Reduce the Profile of Th1, Th2, and Th17 Chemokines and Chemokine Receptors in Cardiac Tissue from Chronic Trypanosoma cruzi-Infected Dogs
}

\author{
Guilherme de Paula Costa, ${ }^{1}$ Laís Roquete Lopes, ${ }^{1}$ Maria Cláudia da Silva, ${ }^{2}$ \\ Aline Luciano Horta, ${ }^{1}$ Washington Martins Pontes, ${ }^{1}$ Cristiane M. Milanezi, ${ }^{2}$ \\ Paulo Marcos da Mata Guedes, ${ }^{3}$ Wanderson Geraldo de Lima, ${ }^{1,4}$ Richard Schulz, ${ }^{5}$ \\ João Santana da Silva, ${ }^{2}$ and Andre Talvani ${ }^{1,4,6}$ \\ ${ }^{1}$ Programa de Pós-Graduação em Ciências Biológicas/NUPEB, Universidade Federal de Ouro Preto, Ouro Preto, MG, Brazil \\ ${ }^{2}$ Faculdade de Medicina de Ribeirão Preto, USP, Ribeirão Preto, SP, Brazil \\ ${ }^{3}$ Universidade Federal do Rio Grande do Norte Federal, Natal, RN, Brazil \\ ${ }^{4}$ Departamento de Ciências Biológicas, Universidade Federal de Ouro Preto, Ouro Preto, MG, Brazil \\ ${ }^{5}$ Departments of Pediatrics \& Pharmacology, Cardiovascular Research Centre, University of Alberta, Edmonton, AB, Canada \\ ${ }^{6}$ Programa de Pós-Graduação em Saúde e Nutrição, Universidade Federal de Ouro Preto, Ouro Preto, MG, Brazil \\ Correspondence should be addressed to Andre Talvani; talvani@nupeb.ufop.br
}

Received 2 April 2016; Revised 14 July 2016; Accepted 4 August 2016

Academic Editor: Sandra Helena Penha Oliveira

Copyright (c) 2016 Guilherme de Paula Costa et al. This is an open access article distributed under the Creative Commons Attribution License, which permits unrestricted use, distribution, and reproduction in any medium, provided the original work is properly cited.

\begin{abstract}
Chemokines (CKs) and chemokine receptors (CKR) promote leukocyte recruitment into cardiac tissue infected by the Trypanosoma cruzi. This study investigated the long-term treatment with subantimicrobial doses of doxycycline (Dox) in association, or not, with benznidazole $(\mathrm{Bz})$ on the expression of CK and CKR in cardiac tissue. Thirty mongrel dogs were infected, or not, with the Berenice78 strain of T. cruzi and grouped according their treatments: (i) two months after infection, Dox (50 mg/kg) 2x/day for 12 months; (ii) nine months after infection, $\mathrm{Bz}(3,5 \mathrm{mg} / \mathrm{Kg}) 2 \mathrm{x} /$ day for 60 days; (iii) Dox + Bz; and (iv) vehicle. After 14 months of infection, hearts were excised and processed for qPCR analysis of Th1 (CCL2, CCL3, CCL4, CCL5, CXCL9, and CXCL11), Th2 (CCL1, CCL17, CCL24, and CCL26), Th17 (CCL20) CKs, Th1 (CCR5, CCR6, and CXCR3), and Th2/Th17 (CCR3, CCR4, and CCR8) CKR, as well as IL-17. T. cruzi infection increases CCL1, CCL2, CCL4, CCL5, CCL17, CXCL10, and CCR5 expression in the heart. Dox, Bz, or Dox $+\mathrm{Bz}$ treatments cause a reversal of CK and CKR and reduce the expression of CCL20, IL-17, CCR6, and CXCR3. Our data reveal an immune modulatory effect of Dox with Bz, during the chronic phase of infection suggesting a promising therapy for cardiac protection.
\end{abstract}

\section{Introduction}

Chemokines are low molecular weight proteins that promote leukocyte trafficking in homeostasis and inflammatory processes. Chronic inflammation is usually characterized by the persistence of leukocyte infiltration into the inflammatory site driven by chemokine production [1-3]. In particular, Trypanosoma cruzi infection is a well-known parasite disease where the presence of this protozoan triggers activation and continued leukocyte infiltration into the muscle tissues in order to eliminate it [4-6]. Since the stimulus persists over months, years, or decades, cell infiltration conducted by Th1 and Th2-like chemokines and their receptors may lead to loss of tissue's architecture and function, in some cases causing severe disability, especially in the heart $[7,8]$.

After the interaction between T. cruzi and mammalian host cells, the activation of innate resident macrophages/ neutrophils combined with the mobilization of natural killer 
cells, TCD4+, TCD8+, and gamma-delta $\mathrm{T}$ cells releases vasoactive substances and inflammatory mediators triggered by the invasion of blood trypomastigote forms of this parasite $[9,10]$. Latter, IL-12 induces a Thl-type differentiation, mediated by IFN- $\gamma$, TNF, and IL-17, culminating in NO biosynthesis by macrophages and in the generation of a panel of inflammatory chemokines that orchestrates and accelerates acute immunopathogenesis [11-13].

On the other hand, chronic cardiac inflammation induced by $T$. cruzi is a harmful and silent event that occurs due to the failure in resolving the acute inflammation and/or due to the persistence of the parasitic stimulus. The involvement and importance of CK and CKR to the generation of the chronic cardiomyopathy induced by $T$. cruzi were previously highlighted by our group, in humans and in experimental animals (rodent and dog) [12, 1417]. Even at this chronic stage, IFN- $\gamma$ and TNF persist as essential cytokines, maintaining the migration of $\mathrm{T}$ cells to consolidate the cardiomyopathy by increasing the expression of CCL5 (RANTES), CCL2 (MCP-1), CXCL10 (IP-10), and CXCL9 (MIG) as well as enhancing intercellular adhesion and vascular cell adhesion molecules [7, 12]. Comprehending the role of $\mathrm{CK}$ and $\mathrm{CKR}$ on immune cells, from acute to chronic cardiac disease, may open new therapies to reduce the damage caused by chronic T. cruzi-induced cardiomyopathy.

In this present study, Dox, a member of the tetracycline family, was investigated based on its capacity to selectively inhibit matrix metalloproteinases and modulate immune response, already at a subantimicrobial dose [18-21]. Dox was tested alone and in combination with the antiparasitic drug, benznidazole (BZ) which also possesses a potential immune modulatory role [22-24]. Assuming the importance of leukocyte recruitment to $T$. cruzi-induced myocarditis, both pharmacological interventions were investigated for their potential interference on the expression of cardiac CK and CKR receptors in dogs infected with the Berenice-78 strain of T. cruzi [25], an experimental model with close similarity to human Chagas myocarditis $[26,27]$.

\section{Materials and Methods}

2.1. Animals, Infection, and Treatments. Thirty mongrel dogs of either sex (4 months old), obtained from the Animal Facility at Universidade Federal de Ouro Preto (UFOP, MG, Brazil), were infected or not with $2 \times 10^{3}$ bloodstream forms of Berenice-78 (Be-78) strain of Trypanosoma cruzi. The animals were fed with a commercial dog food and water ad libitum. Prior to the study they were vaccinated and dewormed against several parasitic diseases.

Male and female animals were grouped $(n=5)$ according to their treatment: (i) doxycycline (Dox) $(50 \mathrm{mg} / \mathrm{kg})$ twice a day for 12 months starting at 2 months after T. cruzi infection, (ii) benznidazole $(\mathrm{Bz})(3,5 \mathrm{mg} / \mathrm{kg})$ twice a day for 60 days starting at the 9th month of infection, (iii) Dox $+\mathrm{Bz}$, and (iv) vehicle ( $0.5 \%$ carboxymethylcellulose, in water). Dox has plasma half-life of $10-12 \mathrm{~h}$, and antimicrobial dosing requires 100-200 mg twice/daily [18]. In parallel, an uninfected group was evaluated during the period of experimentation. Animals were gently immobilized according to the guidelines of the Brazilian College of Animal Experimentation (COBEA), and the administration of medicines and vehicle was performed by a direct injection of $3 \mathrm{~mL}$ of the solution in the oropharynges of the animals using a plastic syringe; the solution was diluted in a soup to facilitate drug administration.

The animals were euthanized at the 14th month after infection and fragments of the left ventricle were stored in $\mathrm{TRIzol}^{\circledR}$ at $-80^{\circ} \mathrm{C}$. All animal experiments and procedures were performed in accordance with the COBEA and approved by the Ethical Committee for Experiments with Laboratory Animals at UFOP (CEUA-UFOP/Protocol number 2013/60).

2.2. RNA Extraction and cDNA Synthesis. Total RNA from cardiac tissues (30-35 mg of left ventricle) were isolated using $0.5 \mathrm{~mL}$ of TRIzol reagent (Invitrogen) or the SV Total RNA Isolation System (Promega, Madson, WI) according to manufacturer's instructions. The RNA yield and the ratio of absorbance at $260-280 \mathrm{~nm}\left(A_{260} / A_{280}\right.$ ratio $)$ were measured using a NanoVue Plus Spectrophotometer (GE Healthcare, $\mathrm{UK})$. Samples containing $<10 \mathrm{ng} / \mu \mathrm{L}$ of RNA were excluded from the study. The cDNA was synthesized using $1 \mu \mathrm{g}$ of total RNA through a reverse transcription reaction (Reverse Transcriptase, Promega). The cDNA $\beta$-actin copy number/RNA $\beta$-actin copy number ratio was calculated as a measure of the efficiency of the cDNA synthesis; this ratio was used to normalize the reference gene copy numbers as assessed by quantitative real-time PCR.

2.3. Development of Real-Time PCR Assays for Canine CK and CKR. For the CK and CKR genes, a standard curve from serial dilutions of a known concentration of purified DNA was achieved. This quantified DNA consists of the target PCR product prepared by conventional PCR, from cDNA positive for the corresponding target mRNA. Threefold measurements, for each standard dilution point over the whole standard curve range, produced to generate a reliable standard curve. Then, real-time PCR quantitative mRNA analyses were performed using an ABI Prism 7000 SDS unit (Applied Biosystems) through the Platinum ${ }^{\circledR} \mathrm{SYBR}^{\circledR}$ Green qPCR SuperMix UDG with ROX reagent (Invitrogen) for quantification of amplicons. The standard PCR conditions were as follows: $50^{\circ} \mathrm{C}(2 \mathrm{~min}), 95^{\circ} \mathrm{C}(10 \mathrm{~min}) ; 40$ cycles of $94^{\circ} \mathrm{C}(30 \mathrm{~s}), 58^{\circ} \mathrm{C}(30 \mathrm{~s})$, and $72^{\circ} \mathrm{C}(1 \mathrm{~min})$, followed by the standard denaturation curve, as performed previously by our group [16]. The sequences of the primers were designed using the Primer Express software (Applied Biosystems) assuming the nucleotide sequences available in the GenBank database (Table 1). In each reaction the Platinum ${ }^{\circledR} \mathrm{SYBR}^{\circledR}$ Green qPCR SuperMix UDG with ROX reagent (Invitrogen), $1 \mu \mathrm{g} / \mu \mathrm{L}$ of each specific primer, and cDNA diluted 20 times were used. In this study, all data were normalized to beta-actin mRNA. Relative increases in CK and CKR were plotted in comparison to the noninfected control group using $2 \Delta \Delta \mathrm{CT}$ method.

2.4. Histopathology. Animals were euthanized at the 14th month after infection and heart tissue fragments with an 
TABle 1: Primer sequences according to the GenBank database.

\begin{tabular}{|c|c|}
\hline & Sequences (forward and reverse) \\
\hline \multirow{2}{*}{ CCL2 } & TAAAAGAGTCACCAGCAGCAA \\
\hline & TTTAGGACGGTCTTGAAGATCA \\
\hline \multirow{2}{*}{ CCL5 } & CAAGCAGATTCCACGCAAGTT \\
\hline & TAATACCGGGCTTGGAGCAT \\
\hline \multirow{2}{*}{ CCL4 } & TGACCGTCCTTTCTCTCCTT \\
\hline & GATCTGAACCCATTGGTGCT \\
\hline \multirow{2}{*}{ CCL5 } & AAGGGCTGACTGATAAATGTGA \\
\hline & AGCGAGAATTTTAATGGAAAGC \\
\hline \multirow{2}{*}{ CCL17 } & CCATCGTGTTTGTAACTGTCCA \\
\hline & АATATCTGACCGCCTTCTTCAC \\
\hline \multirow{2}{*}{ CCL20 } & TATGGTTCCTCCCGGATCTATC \\
\hline & TCATTGGCCAGCTGTTGTTGTGT \\
\hline \multirow{2}{*}{ CCL24 } & CCTGCTGCATGTTCTTCATTTC \\
\hline & TTCTGGTTCTTCTTGGTGGTGA \\
\hline \multirow{2}{*}{ CCL26 } & TCTTCATCCTGAGTGTCCATCG \\
\hline & AGCAGAACTTGGCCACATCA \\
\hline \multirow{2}{*}{ CXCL9 } & CAGATGGTCCTTAAGCCACTTT \\
\hline & CCTTTCCСTGTGAACCTCAA \\
\hline \multirow{2}{*}{ CXCL10 } & CACATGTTGAGATCATTGCCAC \\
\hline & TTCAGACATCTTTTCTCCCCA \\
\hline \multirow{2}{*}{ CCR3 } & CTAGCAGCCTCCССTGAATTTA \\
\hline & TGTTCAGACTCCTTTTGGGACT \\
\hline \multirow{2}{*}{ CCR4 } & TTTGGACTAGGTCTCTGCAAGA \\
\hline & AAAAGCCCACCAGGTACATC \\
\hline \multirow{2}{*}{ CCR5 } & TGTGTCTGCTTCAAAAGCCC \\
\hline & TCACTTGTCACCACCCCAAA \\
\hline \multirow{2}{*}{ CCR6 } & AGCTGTTTGTGCCAATTGCTTA \\
\hline & AAAATATTGCCCAGGAGGCC \\
\hline \multirow{2}{*}{ CCR8 } & TGATATCATCTCAAGCCCCTG \\
\hline & AGCAACTTGCTGTCTCTTTGGA \\
\hline \multirow{2}{*}{ CXCR3 } & TTCTTTGCCATCCCAGATTTC \\
\hline & ATGCATGGCATTTAGGCG \\
\hline \multirow{2}{*}{ IL-17 } & ACTCCAGAAGGCCCTCAGA \\
\hline & GATTCCAAGGTGAGGTAGATCG \\
\hline \multirow{2}{*}{$\beta$-actin } & ССАСТTTCСТGTCTTACССАA \\
\hline & AATTAACCACCCACGGTGTT \\
\hline
\end{tabular}

area of $0.2 \mathrm{~cm}^{2}$ from the middle of the left ventricle wall were taken for histopathology analysis. Tissue fragments were fixed in $10 \%$ buffered formalin solution, dehydrated, cleared, and embedded in paraffin. Blocks were cut into $4 \mathrm{~mm}$ thick sections and stained by hematoxylin and eosin (H\&E) for inflammation assessment. Twenty fields from each hematoxylin and eosin stained sections were randomly chosen at a $40 \mathrm{x}$ magnification, giving an area of $1,5 \times 10^{6} \mu \mathrm{m}^{2}$ of analyzed myocardium. Images were obtained through a Leica DM 5000 microchamber (Leica Application Suite, version 2.4.0R1) and processed by Leica Qwin (V3) image analyzer software. The inflammatory process was estimated using a correlation index of the number of cell nuclei observed in the myocardium from uninfected animals. This index corresponds to the number of nuclei of inflammatory leukocytes plus the background of cardiac cells nuclei observed in the uninfected dog samples.

2.5. Statistical Analysis. Data are expressed as the mean \pm standard error of the mean (SEM) and were analyzed using the Kolmogorov-Smirnov normality test and One-Way analysis of variance. All analyses were performed using PRISM 5.01 software (GraphPad, San Diego, CA, USA) and the level of significance was accepted at $p<0.05$.

\section{Results}

3.1. Chemokine mRNA Expression in Cardiac Tissues from T. cruzi-Infected Animals. The mRNA expression of the Th1 profile chemokines, able to recruit $\mathrm{T}$ cells, monocytes, and memory $\mathrm{T}$ cells, was evaluated in left ventricle from chronically T. cruzi-infected dogs. The parasite was able to induce a high expression of CCL2 (Figure 1(a)), CCL4 (Figure 1(c)), CCL5 (Figure 1(d)), and CXCL10 (Figure 1(f)) when compared to uninfected control animals. At this stage of infection, only CCL3 (Figure 1(b)) and CXCL9 (Figure 1(e)) showed no changes in mRNA expression. In the presence of a long-term treatment with Dox alone or in association with $\mathrm{Bz}$, the mRNA levels of CCL4 and CCL5 were reduced. This profile was also observed in monotherapy with Bz for 60 days, starting at the chronic phase.

The profile of Th2-like chemokines was also evaluated. An increase in the mRNA expression of CCL1 (Figure 2(a)) and CCL17 (Figure 2(b)) in cardiac tissue from infected dogs was seen. The expression of Th2-like chemokines, involved with the recruitment of monocytes and $\mathrm{T}$ cells, reduced after Dox, Dox $+\mathrm{Bz}$, or $\mathrm{Bz}$ therapies. However, the Th2-like chemokines CCL24 (Figure 2(c)) and CCL26 (Figure 2(d)), both involved in eosinophil recruitment, were not enhanced in the presence of the parasite. The associative Dox $+\mathrm{Bz}$ therapy was able to increase the expression of the CCL26 (Eotaxin-3) whereas monotherapy with Bz showed an opposite effect. The Th17-like chemokine CCL20 (MIP$3 \mathrm{~b}$ ) which acts on regulatory and memory $\mathrm{T}$ cells as well as dendritic and B cells also showed high mRNA expression in the left ventricle tissue from T. cruzi-infected animals (Figure 3(a)). Therapies with Dox, Dox $+\mathrm{Bz}$, or Bz were all able to reduce the expression of CCL20. However, IL-17, which has an important role in experimental acute infection with T. cruzi, was not significantly enhanced in the chronic phase of infection with this strain of T. cruzi. (Figure 3(b)).

3.2. The CKR Receptors mRNA Expression in Cardiac Tissues from T. cruzi Infected Animals. The mRNA expression of CKR with Th1 profile, such as CCR5 (Figure 4(a)), whose ligands include CCL3, CCL4, CCL5, CCL11, CCL14, and CCL16, was significantly enhanced in the left ventricle from infected dogs. $\mathrm{Bz}$ reduced this expression, whether alone or in combination with Dox, than monotherapy. The other chemokine receptors with Th1 profile evaluated in this study, CCR6 (Figure 4(b)) and CXCR3 (Figure 4(c)), showed no 


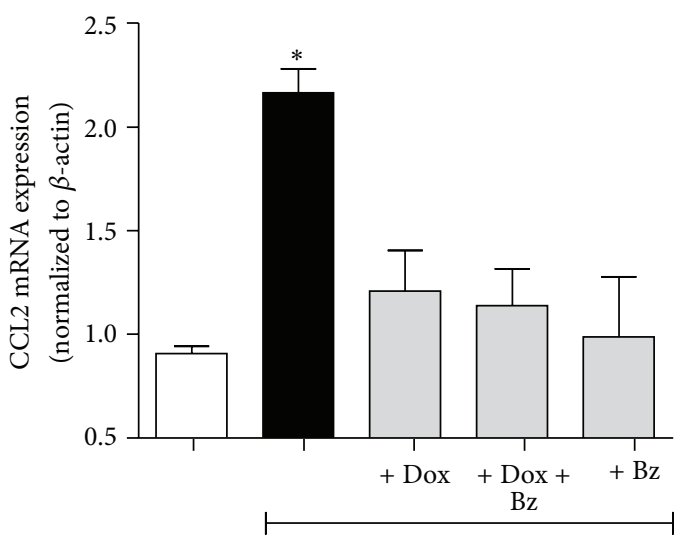

Trypanosoma cruzi infection

(a)

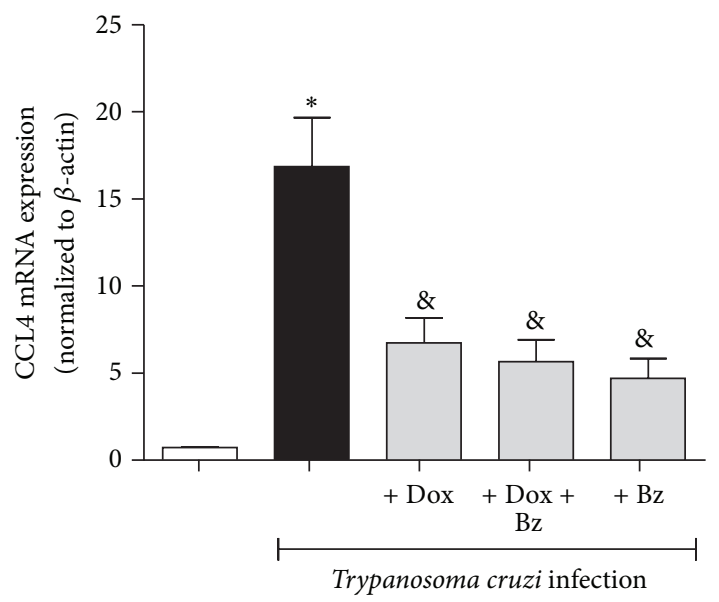

(c)

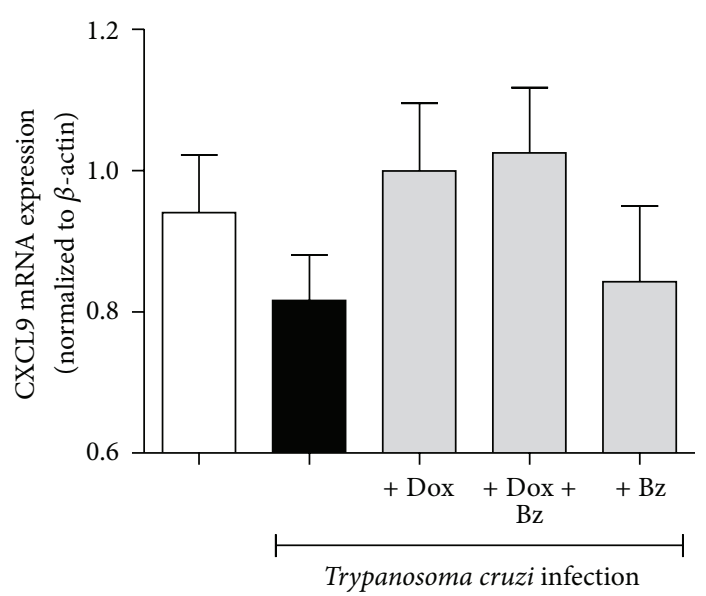

(e)

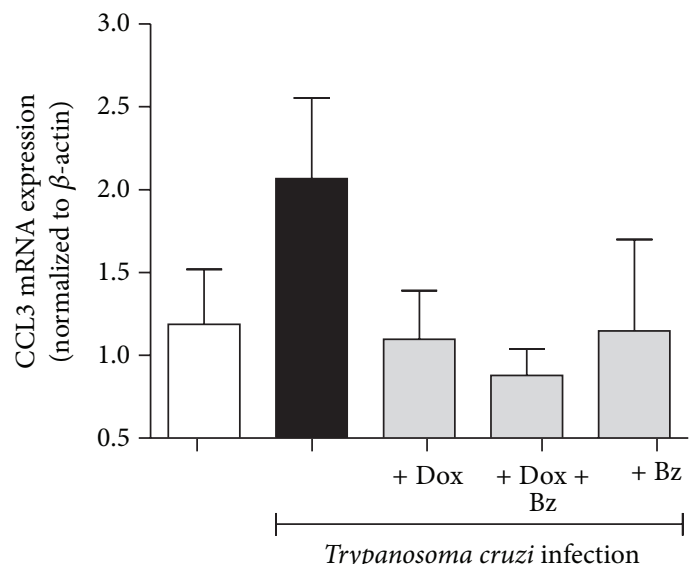

(b)

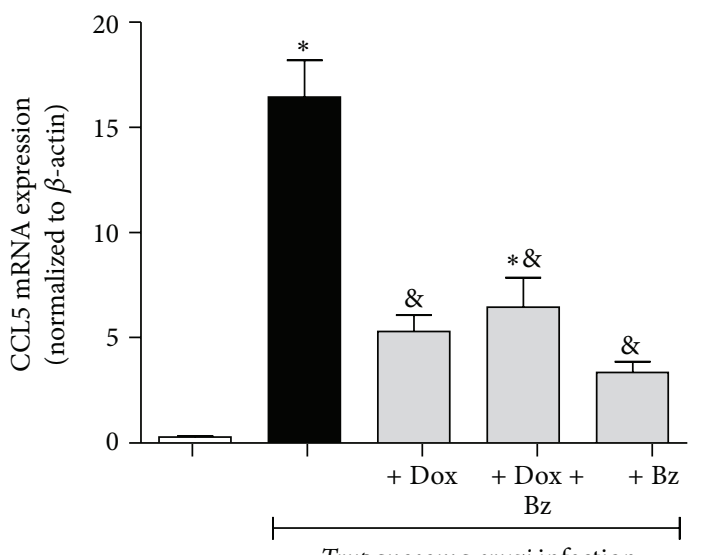

Trypanosoma cruzi infection

(d)

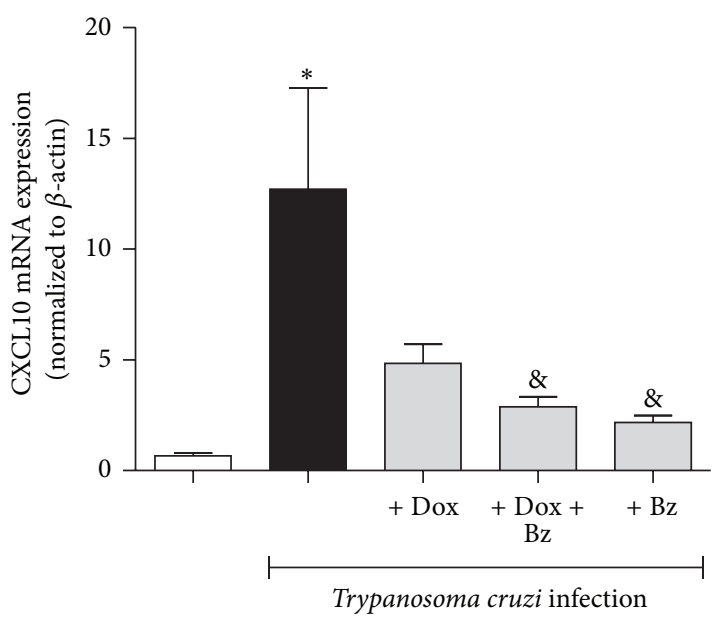

(f)

FIGURE 1: Expression of Thl-like chemokines in the cardiac tissue from dogs infected with Trypanosoma cruzi. Mongrel dogs were infected (black bars), or not (white bars), with Berenice-78 strain of T. cruzi and treated daily for 12 months with doxycycline (Dox), for 60 days with benznidazole $(\mathrm{Bz})$, or in association with Dox + Bz (grey bars) and Th1-like chemokines CCL2, CCL3, CCL4, CCL5, CXCL9, and CXCL10 mRNA expression evaluated in left ventricle tissues from these animals. Data are representative of groups of 5 animals in which expression of chemokines was normalized to the constitutive beta-actin. ${ }^{*} p<0.05$ in relation to the noninfected group; ${ }^{*} p<0.05$ in relation to the infected group without treatment. 


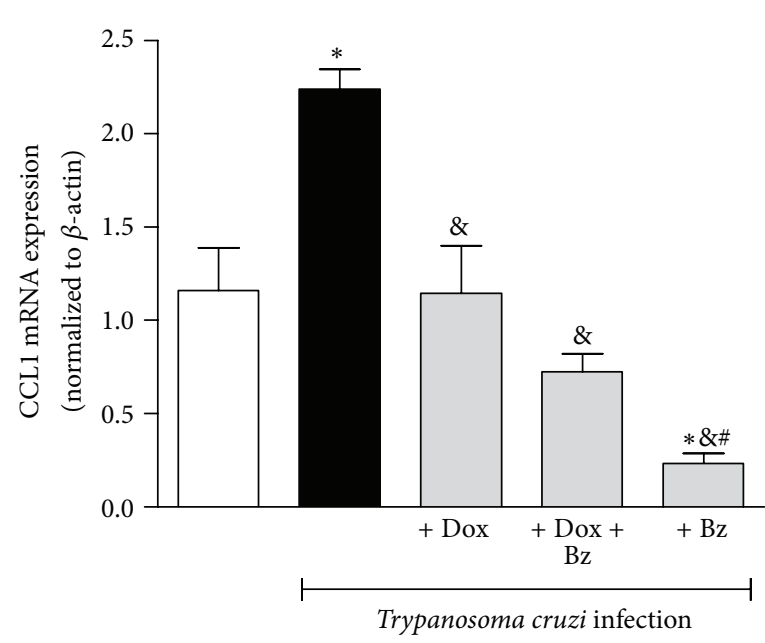

(a)

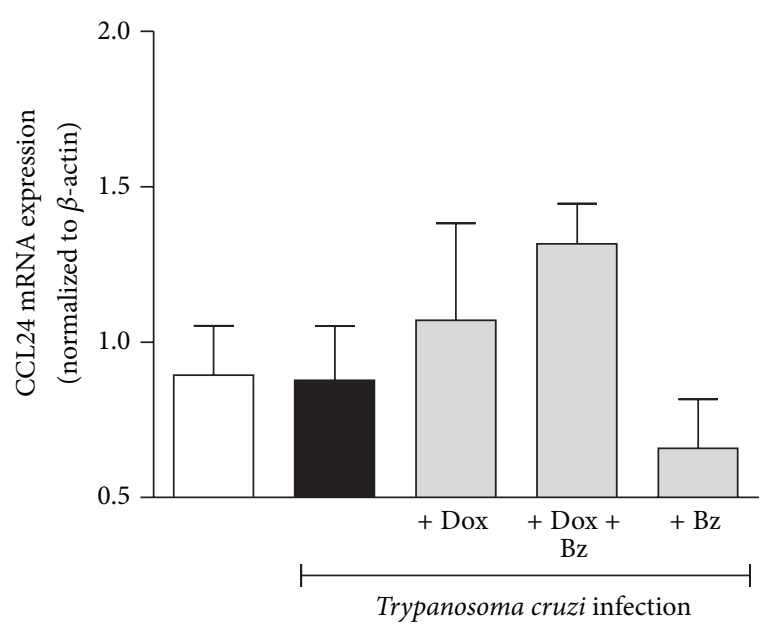

(c)

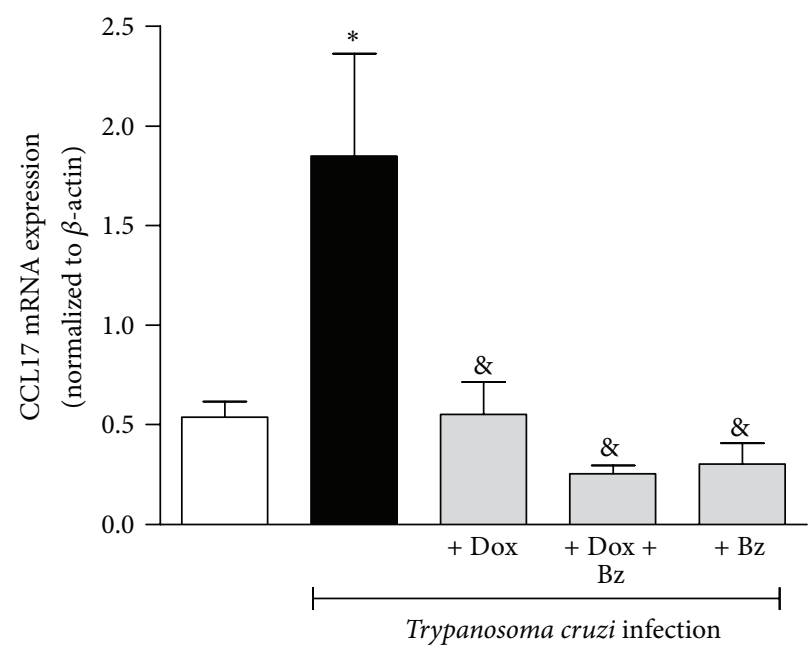

(b)

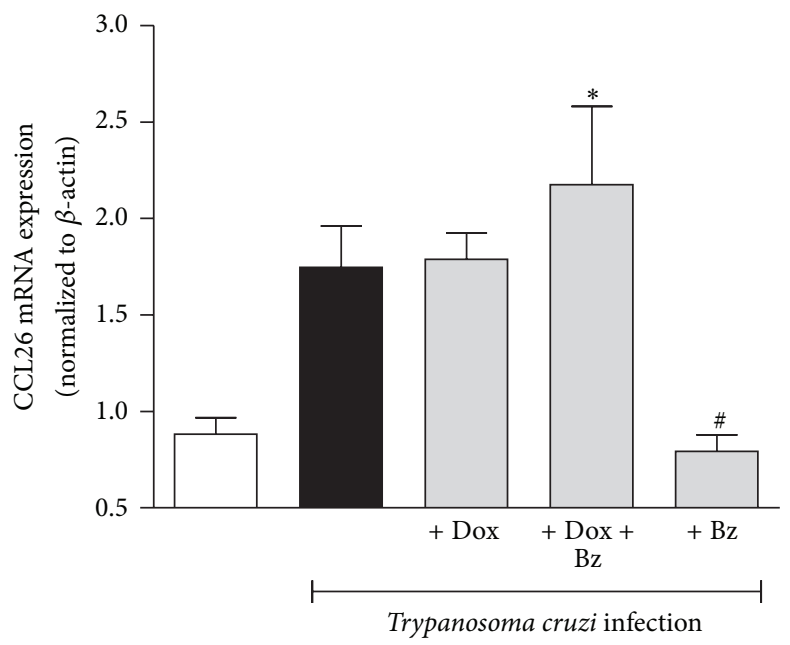

(d)

Figure 2: Expression of Th2-like chemokines in the cardiac tissue Trypanosoma cruzi-infected dogs. Th2-like chemokines CCL1, CCL17, CCL24, and CCL26 mRNA expression evaluated in left ventricle tissues. Data are representative of the groups ( $n=5$ animals) in which the expression of chemokines was normalized to the constitutive beta-actin. $*$ means difference $(p<0.05)$ in relation to the noninfected group; $\&$ means difference $(p<0.05)$ in relation to the infected group without treatment; \# means difference $(p<0.05)$ in relation to the Dox and Dox $+B z$

significant changes following T. cruzi infection. However, for both receptors, the combination or the monotherapies were able to decrease their mRNA expression, less than in the uninfected dogs, except to the CXCR3 in dogs under Dox treatment (Figure 4(c)).

In partial accordance with the expression in the pattern of some Th2/Th17 CK, the expressions of Th2/Th17 profile of CKR CCR3 (Figure 5(a)), CCR4 (Figure 5(b)), and CCR8 (Figure 5(c)) were also unchanged in dogs infected. Even so, the combination therapy Dox $+\mathrm{Bz}$ reduced the mRNA expression of all CKR when compared with the level seen in infected cardiac tissues.

3.3. Leukocyte Infiltration in Left Ventricular Tissue. CK and CKR were evaluated, in parallel, with the evidence of leukocyte infiltration in the left ventricle tissue, by estimating the total cell nuclei (cardiac cells and leukocytes infiltrated into the cardiac tissue). Chronic T. cruzi-infected dogs presented scattered infiltrating cells whereas there was an absence of detectable cellular infiltration in uninfected animals and in infected dogs treated with Dox for 12 months and with $\mathrm{Bz}$ for 60 days during the chronic infection phase (Figure 6), in monotherapy or in combination.

\section{Discussion}

In this present study, an associative and a long-term therapy with $\mathrm{Bz}$ and Dox was proposed to mongrel dogs infected with the Berenice-78 strain of $T$. cruzi. We observed a significant reduction of mRNA expression to the Th1 and Th2/Th17-like CK/CKR, as well as to IL-17 in the left ventricle tissue in association with $\mathrm{Bz}$ and Dox therapies. 


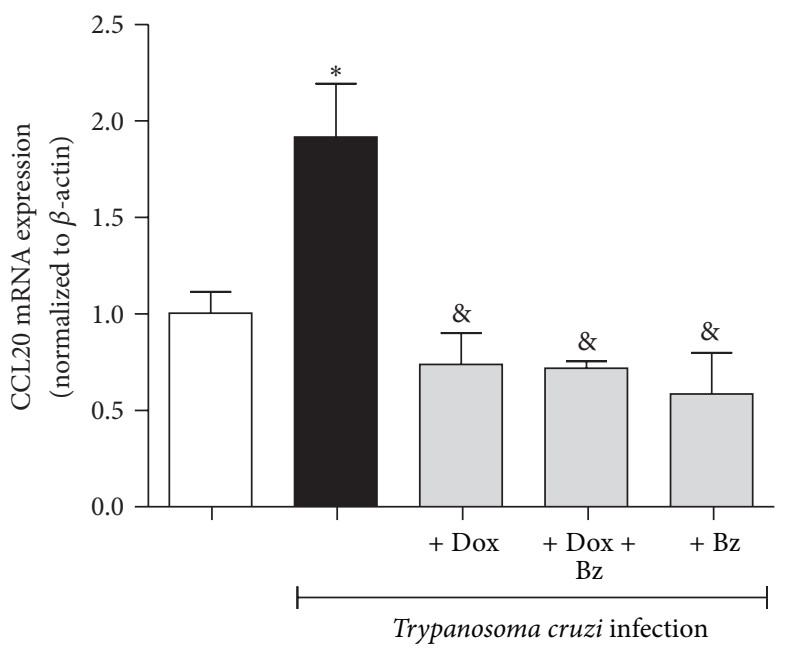

(a)

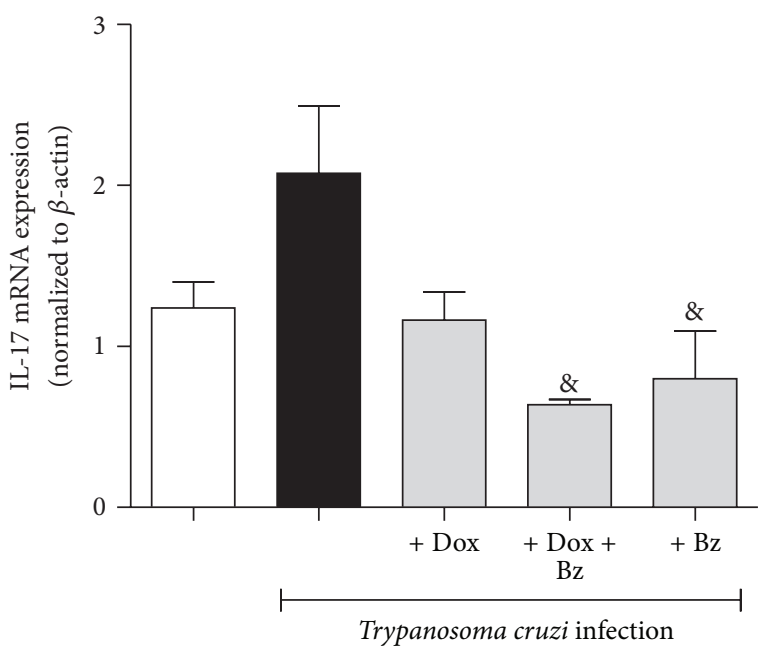

(b)

FIGURE 3: Expression of Th17-like chemokine CCL20 and IL-17 in the cardiac tissue from dogs infected with Trypanosoma cruzi. CCL20 and IL-17 mRNA expression evaluated in left ventricle tissues. Data are representative of groups $(n=5$ animals) in which expression of chemokines was normalized to the constitutive beta-actin. \& means difference $(p<0.05)$ in relation to the infected group without treatment; * means difference $(p<0.05)$ in relation to the noninfected group.

This fine tuning between pharmacological intervention and CK/CKR expression may result in a gradual protection with low inflammatory infiltration, low cellular destruction, and cardiac architecture preservation.

The concepts of T. cruzi-induced inflammation as the trigger of cardiac remodeling are essential since parasites can persist in the host tissues. Bz is the main drug currently used to eliminate this parasitic infection; however, its effectiveness is observed only when administered during the initial stage of infection $[28,29]$. New pharmacological strategies have been proposed in experimental models aiming at not only eliminating the parasite but also modulating the inflammatory mediators through the reduction of the release and expression of cytokines and CKs, systemically and in the infected heart tissue.

The relevance of the chemokine network to the generation and progression of the cardiomyopathy induced by T. cruzi has gained strong evidence in different experimental models as well as in studies involving individuals with chronic Chagas cardiomyopathy [8,30-32]. After the T. cruzi invasion, activation of the resident immune and endothelial cells precedes the enhanced expression of adhesion molecules, intensifying the recruitment of monocytes, neutrophils, and T cells towards infected muscle, in particular into the cardiac tissue [33, 34]. CKs and their receptors have awaken the immune system towards this infected environment, worsening the pathological cardiac condition and perpetuating it, since the antigenic stimuli are usually not completely eliminated.

Dogs infected with Berenice-78 T. cruzi strain were previously described by de Lana et al. [26], highlighting this "dog model" as the ideal to study experimental T. cruzi-induced cardiomyopathy due to the similarity between clinical and immune parameters with those observed in humans. In particular, the Berenice-78 strain of T. cruzi induces a prominent focal and diffuse fibrosis in the myocardium. In Berenice78 infected dogs, the background of the inflammatory status during the chronic phase does not appear to be dependent on IL-17 or CCL20/CCR6. This latter ligand-receptor pair exerts chemoattraction to B cells, immature dendritic cells, effector, and memory $\mathrm{T}$ cells and also plays a role at the skin, mucosal, and intestinal immune system [35]. IL-17 is an essential mediator acting to resolve T. cruzi infection in mice by increasing STAT-3 and RORgt mRNA, which reflects on the expression of Thl-type chemokines involved with $\mathrm{T}$ cell recruitment (CCL2, CCL3, CCL4, CCL11, and CXCL9) [36]. IL-17 produced by TCD4+, TCD8+, and NK cells are, in part, induced by trypomastigote forms of the parasite in the murine model which suggests its participation centered on the acute phase of infection. Concerning the CKs with Th2profile, there was an increased expression of CCL1 and CCL17 in infected left ventricles. This CCL1-CCR8 axis is linked to the adaptive immune response, possibly influenced by GPI-mucin antigenic stimuli from T. cruzi during the recent chronic phase of infection [37]. Similarly, CCL17, but not its shared receptor CCR4, was also enhanced in these infected dog hearts. This Th2 chemokine, which participates in the development of local fibrosis and in atherosclerotic plaque inflammation, may act to locally constrain the regulatory $\mathrm{T}$ cells (Treg) maintenance and thereby intensify vascular inflammation [38].

The Thl-type CKs are the most important mediators expressed in the myocardium of dogs infected with the Berenice-78 strain of T. cruzi. Similar findings were demonstrated in human hearts, where the mRNA expressions of the CKs CCL5, CXCL9, CXCL10, CCL17, CCL19, and their receptors were upregulated in chronic Chagas cardiomyopathy [31]. The enhancement of CCR5 expression with its ligands CCL3, CCL4, and CCL5 in the parasite infected 


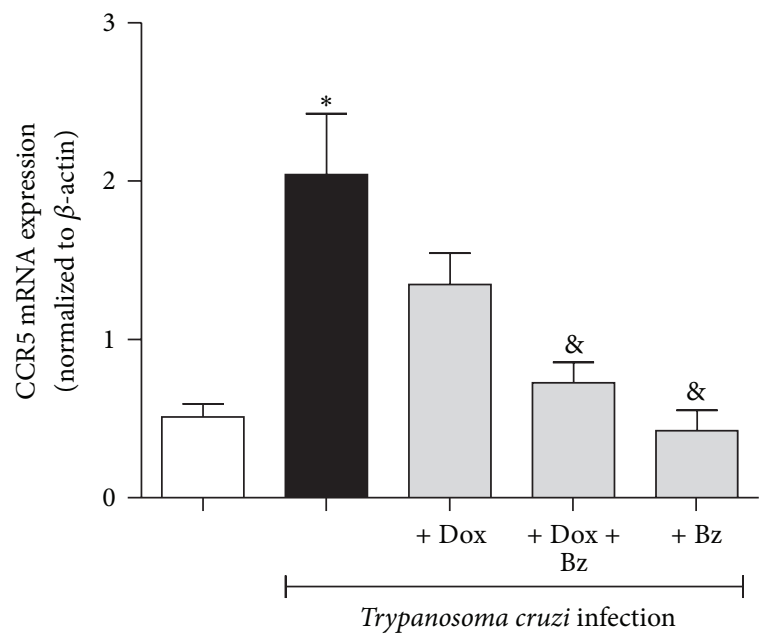

(a)

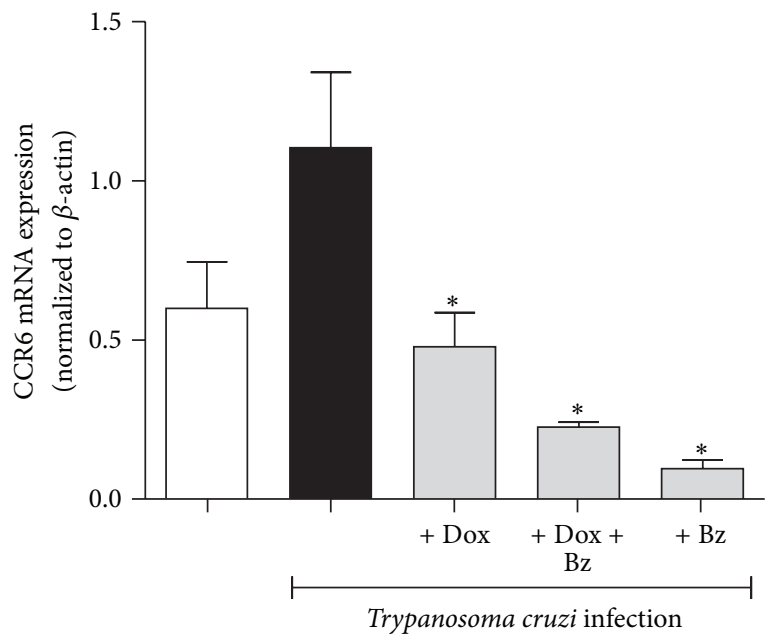

(b)

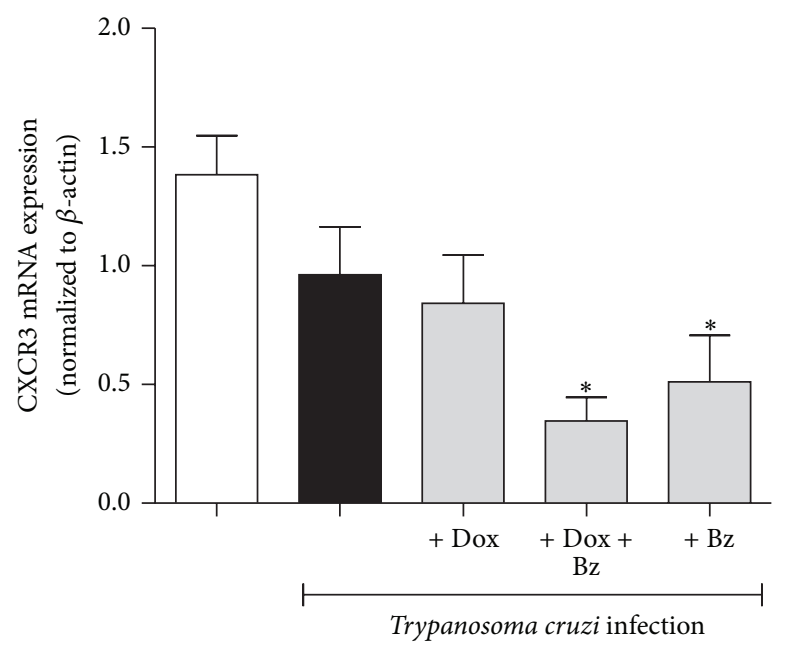

(c)

FIgURE 4: Expression of Th1-like chemokine receptors in the cardiac tissue Trypanosoma cruzi-infected dogs. Th1-like chemokine receptors (CCR5, CCR6, and CXCR3) mRNA expression evaluated in the left ventricle tissues. Data are representative of the groups ( $n=5$ animals) in which the expression of chemokine receptors was normalized to the constitutive beta-actin. $*$ means difference $(p<0.05)$ in relation to the noninfected group; \& means difference $(p<0.05)$ in relation to the infected group without treatment.

tissue is consistent with its important role in promoting leukocyte (CD8+ T cells and monocytes) infiltration within target organs as well as limiting parasite replication during early T. cruzi infection [39]. Leukocytes from individuals with chronic Chagas cardiomyopathy showed high expression of CCR5 and low expression of CXCR4 and this pattern clearly correlates with heart function [15]. In addition, polymorphism in the CCR5-2733 and CCR5-2554 T alleles was associated with the reduced risk of susceptibility and severity to the development of Chagas cardiomyopathy, respectively [40]. Expressions of CKs and their receptors have been shown to be important prognostic markers, since CCL5 and CCL9 chemokine genes were upregulated in heart tissue from individuals with Chagas cardiomyopathy [41]. Of note, similar studies in beagle dogs reinforced that mRNAs of CKs with a Th1-like profile (CCL4, CCL5, CCL26, and CXCR3) are overexpressed in animals presenting chronic cardiomyopathy [16] as well in this present study using chronic T. cruziinfected mongrel dogs where higher expressions of CCL2, CCL4, CCL5, CXCL10, and CCR5 were also observed in the left ventricle associated with low ejection fraction (data not shown). These data are consistent with locally released Th1CKs assisting in the accumulation of Th1 T cells into the T. cruzi-infected cardiac tissue previously described in humans and in animal models.

However, the highlighted and most promising discovery from this study is the use of Dox as a modulator of the CK network in infected cardiac tissue. Doxycycline is noted for its significant effect on its dose-dependent modulation of inflammatory mediators (TNF, IL-1beta, IL-6, IL-8, CCL2, 


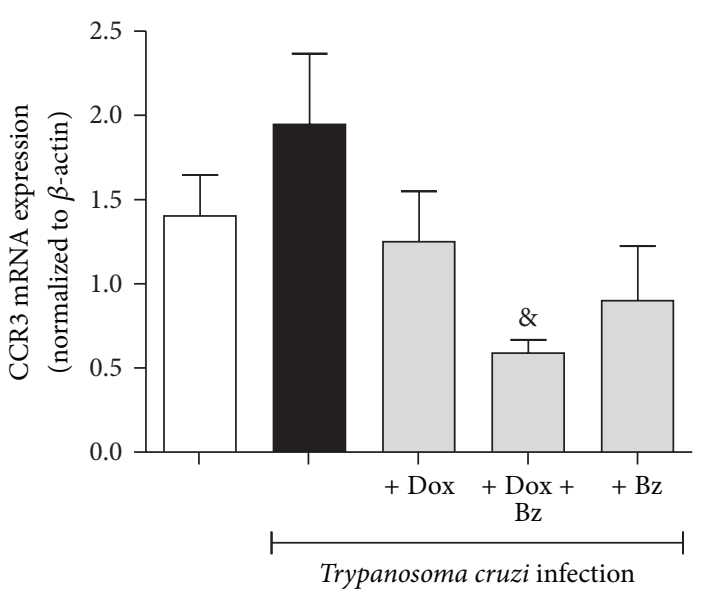

(a)

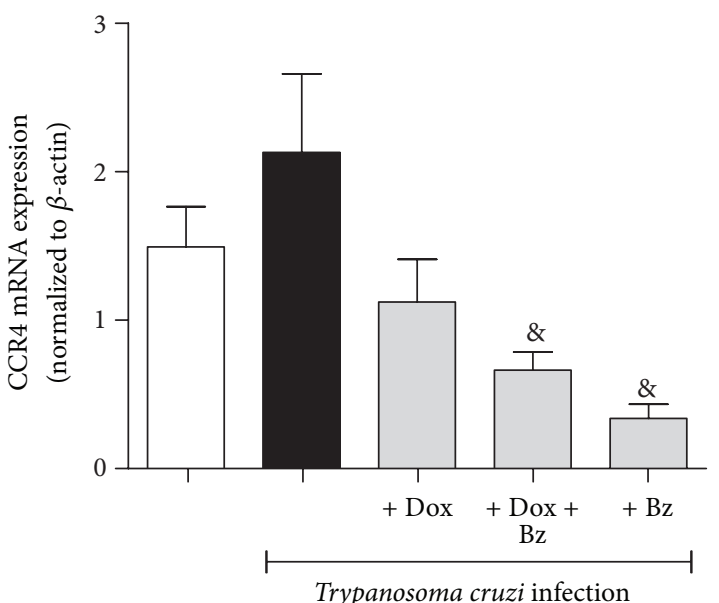

(b)

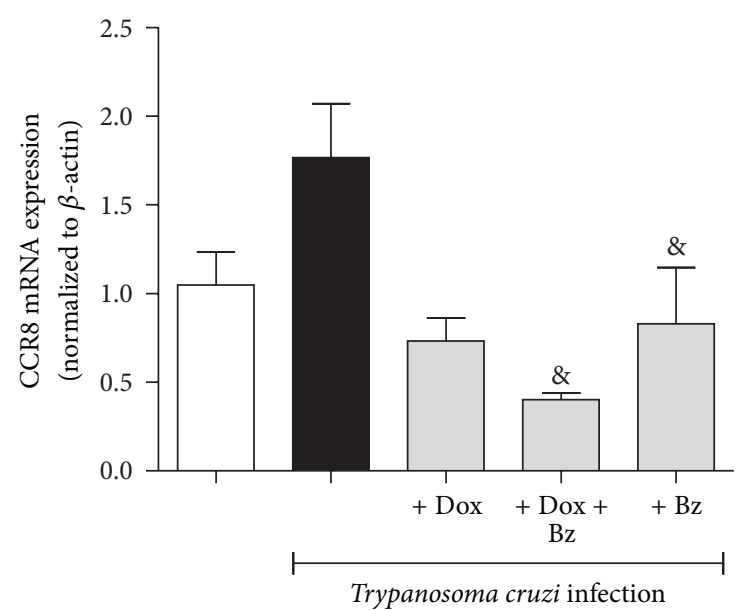

(c)

FiguRE 5: Expression of Th2/Th17-like chemokine receptors in the cardiac tissue from dogs infected with the Trypanosoma cruzi. Th2/TH17like chemokine receptors (CCR3, CCR4, and CCR8) mRNA expression evaluated in the left ventricle tissues. Data are representative of the groups ( $n=5$ animals) in which the expression of chemokine receptors was normalized to the constitutive beta-actin. \& means difference $(p<0.05)$ in relation to the infected group without treatment.

CCL3, and CCL4) in different types of cell lines [42, 43]. Previous studies supported its property to inhibit $\mathrm{T}$ cell proliferation and the cytokine/CK release in peripheral blood mononuclear cells stimulated by staphylococcal exotoxins stimuli [44] and also to prevent lipopolysaccharide-induced endothelial barrier dysfunction by inhibiting the activation of the p38/MAPK pathway in endothelial cells from human umbilical vein [45]. In some human disorders where inflammatory status and protease activities go hand-in-hand as in osteoarthritis, angiogenesis, ulcers, and others, the beneficial effects of doxycycline are not due to its antimicrobial properties, but rather its ability to inhibit matrix metalloproteinase activities. In note, besides the already described inhibitory effects of the doxycycline on matrix metalloproteinase in hearts from T. cruzi-infected mice [46], here we hypothesized that Dox was acting, in the infected mongrel dogs, through the cytokines/CK production reducing cardiac inflammation and the clinical repercussions at the end-stage of this infection.

\section{Conclusions}

In summary, our data demonstrates the importance of therapeutic, long-term intervention with submicrobial dosing of Dox in association with chronic treatment with $\mathrm{Bz}$ in order to decrease or retard the development of T. cruzi-induced cardiac injury through the modulation of the expression of the Th1- and Th2/Th17-like CK/CKR axis in the cardiac left ventricle. In addition, this study reinforces the need for the discovery of new therapies with less toxicity, not only focusing on parasite elimination but also modulating the immune response against cardiac chronic infection. This harmonic equilibrium may be essential to prevent adverse 

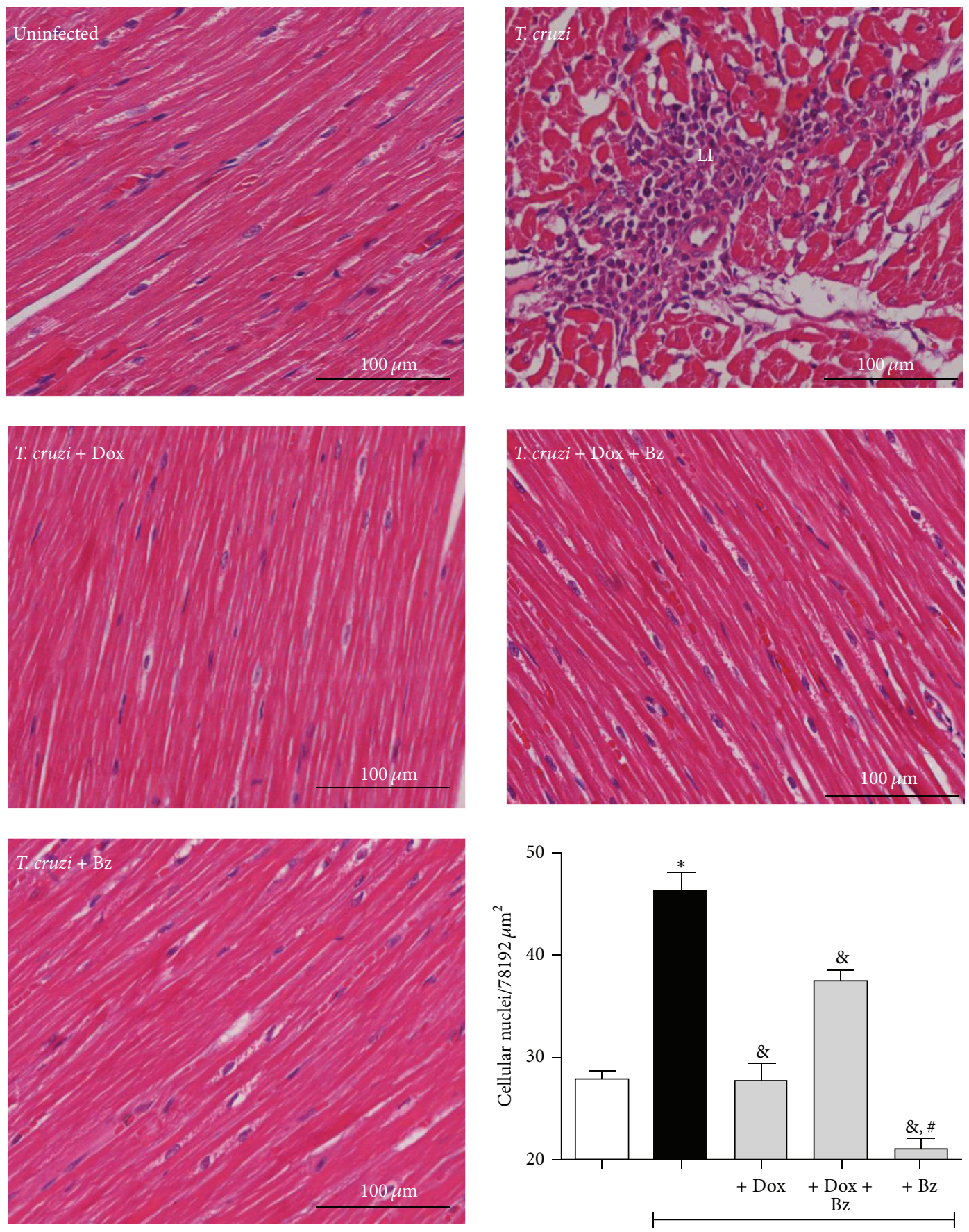

Trypanosoma cruzi infection

Figure 6: Benznidazole and doxycycline reduce inflammation in the T. cruzi-infected left ventricle. Mongrel dogs infected with T. cruzi and treated with doxycycline (Dox), with benznidazole (Bz), or with the association of Dox $+\mathrm{Bz}$ had their heart extracted in the chronic phase to evaluate the inflammatory infiltration (H\&E) in the left ventricle segment. The noninfected group was evaluated in parallel and sections were quantified in sections with 40x of magnification. Data are representative of the groups $\left(n=5\right.$ animals) and ${ }^{*} p<0.05$ in relation to the noninfected group; ${ }^{8} p<0.05$ in relation to the infected group without treatment; \# means difference $(p<0.05)$ in relation to the Dox and Dox + Bz. LI: leukocytes infiltration. 
cardiac remodeling as well as to increase the lifespan of individuals infected with the T. cruzi.

\section{Competing Interests}

The authors declare no competing interests regarding the publication.

\section{Authors' Contributions}

Guilherme de Paula Costa and Laís Roquete Lopes contributed equally to this work.

\section{Acknowledgments}

This work was supported by grants from the Conselho Nacional de Desenvolvimento Científico e Tecnológico (CNPq), Fundação de Amparo à Pesquisa do Estado de Minas Gerais (FAPEMIG APQ-02360-15), and the Universidade Federal de Ouro Preto (UFOP). The authors Andre Talvani, João Santana da Silva, and Paulo Marcos da Mata Guedes thank $\mathrm{CNPq}$ for the fellowship granted to the research in productivity. Coauthors also thank CAPES and FAPEMIG for graduate fellowship support.

\section{References}

[1] P. J. Koelink, S. A. Overbeek, S. Braber et al., "Targeting chemokine receptors in chronic inflammatory diseases: an extensive review," Pharmacology \& Therapeutics, vol. 133, no. 1, pp. 1-18, 2012.

[2] A. Katsounas, M. Trippler, S. Kottilil, R. A. Lempicki, G. Gerken, and J. F. Schlaak, "Cytokine/chemokine patterns connect host and viral characteristics with clinics during chronic hepatitis C," European Journal of Medical Research, vol. 17, no. 1, article 9, 2012.

[3] V. Kim, W. D. Cornwell, M. Oros, H. Durra, G. J. Criner, and T. J. Rogers, "Plasma Chemokine signature correlates with lung goblet cell hyperplasia in smokers with and without chronic obstructive pulmonary disease," BMC Pulmonary Medicine, vol. 15, pp. 111-121, 2015.

[4] C. Junqueira, B. Caetano, D. C. Bartholomeu et al., "The endless race between Trypanosoma cruzi and host immunity: lessons for and beyond Chagas disease," Expert Reviews in Molecular Medicine, vol. 12, article e29, 2010.

[5] D. Andrade, R. Serra, E. Svensjö et al., "Trypanosoma cruzi invades host cells through the activation of endothelin and bradykinin receptors: a converging pathway leading to chagasic vasculopathy," British Journal of Pharmacology, vol. 165, no. 5, pp. 1333-1347, 2012.

[6] M. S. Cardoso, J. L. Reis-Cunha, and D. C. Bartholomeu, "Evasion of the immune response by Trypanosoma cruzi during acute infection," Frontiers in Immunology, vol. 6, article 659, 2016.

[7] J. Lannes-Vieira, J. C. Silverio, I. R. Pereira et al., "Chronic Trypanosoma cruzi-elicited cardiomyopathy: from the discovery to the proposal of rational therapeutic interventions targeting cell adhesion molecules and chemokine receptors-how to make a dream come true," Memorias do Instituto Oswaldo Cruz, vol. 104, no. 1, pp. 226-235, 2009.
[8] A. Talvani and M. M. Teixeira, "Inflammation and chagas disease: some mechanisms and relevance," Advances in Parasitology, vol. 76, pp. 171-194, 2011.

[9] N. A. Guerrero, M. Camacho, L. Vila et al., "Cyclooxygenase-2 and prostaglandin $\mathrm{E}_{2}$ signaling through prostaglandin receptor EP-2 favor the development of myocarditis during acute trypanosoma cruzi infection," PLoS Neglected Tropical Diseases, vol. 9, no. 8, Article ID e0004025, 2015.

[10] L. Esper, A. Talvani, P. Pimentel, M. M. Teixeira, and F. S. Machado, "Molecular mechanisms of myocarditis caused by Trypanosoma cruzi," Current Opinion in Infectious Diseases, vol. 28, no. 3, pp. 246-252, 2015.

[11] J. S. Silva, J. C. Aliberti, G. A. Martins, M. A. Souza, J. T. Souto, and M. A. Pádua, "The role of IL-12 in experimental Trypanosoma cruzi infection," Brazilian Journal of Medical and Biological Research, vol. 31, no. 1, pp. 111-115, 1998.

[12] A. Talvani, C. S. Ribeiro, J. C. S. Aliberti et al., "Kinetics of cytokine gene expression in experimental chagasic cardiomyopathy: tissue parasitism and endogenous IFN- $\gamma$ as important determinants of chemokine mRNA expression during infection with Trypanosoma cruzi," Microbes and Infection, vol. 2, no. 8, pp. 851-866, 2000.

[13] V. Brazão, R. P. Colato, F. H. Santello et al., "Interleukin-17, oxidative stress, and inflammation: role of melatonin during Trypanosoma cruzi infection," Journal of Pineal Research, vol. 59, no. 4, pp. 488-496, 2015.

[14] A. Talvani, M. O. C. Rocha, L. S. Barcelos, Y. M. Gomes, A. L. Ribeiro, and M. M. Teixeira, "Elevated concentrations of CCL2 and tumor necrosis factor- $\alpha$ in chagasic cardiomyopathy," Clinical Infectious Diseases, vol. 38, no. 7, pp. 943-950, 2004.

[15] A. Talvani, M. O. C. Rocha, A. L. Ribeiro, R. Correa-Oliveira, and M. M. Teixeira, "Chemokine receptor expression on the surface of peripheral blood mononuclear cells in Chagas disease," The Journal of Infectious Diseases, vol. 189, no. 2, pp. 214220, 2004.

[16] P. M. M. Guedes, V. M. Veloso, A. Talvani et al., "Increased type 1 chemokine expression in experimental Chagas disease correlates with cardiac pathology in beagle dogs," Veterinary Immunology and Immunopathology, vol. 138, no. 1-2, pp. 106113, 2010.

[17] A. R. Penitente, A. L. J. Leite, G. de Paula Costa et al., "Enalapril in combination with benznidazole reduces cardiac inflammation and creatine kinases in mice chronically infected with Trypanosoma cruzi," The American Journal of Tropical Medicine and Hygiene, vol. 93, no. 5, pp. 976-982, 2015.

[18] B. A. Cunha, C. M. Sibley, and A. M. Ristuccia, "Doxycycline," Therapeutic Drug Monitoring, vol. 4, pp. 115-126, 1982.

[19] M. M. Castro, A. D. Kandasamy, N. Youssef, and R. Schulz, "Matrix metalloproteinase inhibitor properties of tetracyclines: therapeutic potential in cardiovascular diseases," Pharmacological Research, vol. 64, no. 6, pp. 551-560, 2011.

[20] G. Cerisano, P. Buonamici, R. Valenti et al., "Effects of a timely therapy with doxycycline on the left ventricular remodeling according to the pre-procedural TIMI flow grade in patients with ST-elevation acute myocardial infarction," Basic Research in Cardiology, vol. 109, no. 4, article 412, 2014.

[21] A. Villaescusa, M. García-Sancho, F. Rodríguez-Franco, M. Á. Tesouro, and Á. Sainz, "Effects of doxycycline on haematology, blood chemistry and peripheral blood lymphocyte subsets of healthy dogs and dogs naturally infected with Ehrlichia canis," Veterinary Journal, vol. 204, no. 3, pp. 263-268, 2015. 
[22] R. Sathler-Avelar, D. M. Vitelli-Avelar, R. L. Massara et al., "Benznidazole treatment during early-indeterminate Chagas' disease shifted the cytokine expression by innate and adaptive immunity cells toward a type 1-modulated immune profile," Scandinavian Journal of Immunology, vol. 64, no. 5, pp. 554-563, 2006.

[23] S. A. Laucella, D. P. Mazliah, G. Bertocchi et al., "Changes in Trypanosoma cruzi-specific immune responses after treatment: surrogate markers of treatment efficacy," Clinical Infectious Diseases, vol. 49, no. 11, pp. 1675-1684, 2009.

[24] R. A. Cutrullis, G. F. Moscatelli, S. Moroni et al., "Benznidazole therapy modulates interferon- $\gamma$ and M2 muscarinic receptor autoantibody responses in Trypanosoma cruzi-infected children," PLoS ONE, vol. 6, no. 10, Article ID e27133, 2011.

[25] M. Lana and C. de Andrade Chiari, "Caracterização biológica comparativa das cepas Berenice e Berenice-78 de Trypanosoma cruzi isoladas da mesma paciente em diferentes períodos," Memórias do Instituto Oswaldo Cruz, vol. 81, no. 3, pp. 247-253, 1986.

[26] M. de Lana, E. Chiari, and W. L. Tafuri, "Experimental Chagas' disease in dogs," Memórias do Instituto Oswaldo Cruz, vol. 87, no. 1, pp. 59-71, 1992.

[27] P. M. M. Guedes, V. M. Veloso, M. V. Caliari et al., "Trypanosoma cruzi high infectivity in vitro is related to cardiac lesions during long-term infection in Beagle dogs," Memorias do Instituto Oswaldo Cruz, vol. 102, no. 2, pp. 141-147, 2007.

[28] Z. Brener, "Recent advances in the chemotherapy of Chagas' disease," Memórias do Instituto Oswaldo Cruz, vol. 79, pp. 149$155,1984$.

[29] J. A. Urbina, "Ergosterol biosynthesis and drug development for Chagas disease," Memórias do Instituto Oswaldo Cruz, vol. 104, no. 1, pp. 311-318, 2009.

[30] F. S. Machado, W. O. Dutra, L. Esper et al., "Current understanding of immunity to Trypanosoma cruzi infection and pathogenesis of Chagas disease," Seminars in Immunopathology, vol. 34, no. 6, pp. 753-770, 2012.

[31] L. G. Nogueira, R. H. Santos, B. M. Ianni et al., "Myocardial chemokine expression and intensity of myocarditis in chagas cardiomyopathy are controlled by polymorphisms in CXCL9 and CXCL10," PLoS Neglected Tropical Diseases, vol. 6, no. 10, Article ID e1867, 2012.

[32] S. M. de Souza, P. M. de Abreu Vieira, B. M. Roatt et al., "Dogs infected with the blood trypomastigote form of Trypanosoma cruzi display an increase expression of cytokines and chemokines plus an intense cardiac parasitism during acute infection," Molecular Immunology, vol. 58, no. 1, pp. 92-97, 2014.

[33] J. Scharftein and A. P. C. A. Lima, "Roles of naturally ocxurring protease inhibitors in the modulation of host cell signaling and cellular invasion by Trypanosoma cruzi," Sub-Cellular Biochemistry, vol. 47, pp. 140-154, 2008.

[34] P. S. Romano, J. A. Cueto, A. F. Casassa, M. C. Vanrell, R. A. Gottlieb, and M. I. Colombo, "Molecular and cellular mechanisms involved in the Trypanosoma cruzi/host cell interplay," IUBMB Life, vol. 64, no. 5, pp. 387-396, 2012.

[35] L. Zhao, J. Xia, X. Wang, and F. Xu, "Transcriptional regulation of CCL20 expression," Microbes and Infection, vol. 16, no. 10, pp. 864-870, 2014.

[36] P. M. D. M. Guedes, F. R. S. Gutierrez, F. L. Maia et al., "IL-17 produced during Trypanosoma cruzi infection plays a central role in regulating parasite-induced myocarditis," PLoS Neglected Tropical Diseases, vol. 4, no. 2, article e604, 2010.
[37] T. Oshio, R. Kawashima, Y. I. Kawamura et al., "Chemokine receptor CCR8 is required for lipopolysaccharide-triggered cytokine production in mouse peritoneal macrophages," PLoS ONE, vol. 9, no. 4, Article ID e94445, 2014.

[38] C. Weber, S. Meiler, Y. Döring et al., "CCL17-expressing dendritic cells drive atherosclerosis by restraining regulatory $\mathrm{T}$ cell homeostasis in mice," The Journal of Clinical Investigation, vol. 121, no. 7, pp. 2898-2910, 2011.

[39] J. L. Hardison, R. A. Wrightsman, P. M. Carpenter, W. A. Kuziel, T. E. Lane, and J. E. Manning, "The CC chemokine receptor 5 is important in control of parasite replication and acute cardiac inflammation following infection with Trypanosoma cruzi," Infection and Immunity, vol. 74, no. 1, pp. 135-143, 2006.

[40] O. Flórez, J. Martín, and C. I. González, "Genetic variants in the chemokines and chemokine receptors in Chagas disease," Human Immunology, vol. 73, no. 8, pp. 852-858, 2012.

[41] E. Cunha-Neto and C. Chevillard, "Chagas disease cardiomyopathy: immunopathology and genetics," Mediators of Inflammation, vol. 2014, Article ID 683230, 11 pages, 2014.

[42] R. Li, X. Luo, Q. Pan et al., "Doxycycline alters the expression of inflammatory and immune-related cytokines and chemokines in human endometrial cells: implication in irregular uterine bleeding," Human Reproduction, vol. 21, no. 10, pp. 2555-2563, 2006.

[43] R. Joks and H. G. Durkin, "Non-antibiotic properties of tetracyclines as anti-allergy and asthma drugs," Pharmacological Research, vol. 64, no. 6, pp. 602-609, 2011.

[44] T. Krakauer and M. Buckley, "Doxycycline is anti-inflammatory and inhibits staphylococcal exotoxin-induced cytokines and chemokines," Antimicrobial Agents and Chemotherapy, vol. 47, no. 11, pp. 3630-3633, 2003.

[45] J.-L. Xia, L.-Q. Wang, L.-L. Wu, and Q.-B. Huang, "Doxycycline hyclate protects lipopolysaccharide-induced endothelial barrier dysfunction by inhibiting the activation of p38 mitogenactivated protein kinase," Biological and Pharmaceutical Bulletin, vol. 37, no. 12, pp. 1882-1890, 2014.

[46] F. R. S. Gutierrez, M. M. Lalu, F. S. Mariano et al., "Increased activities of cardiac matrix metalloproteinases matrix metalloproteinase (MMP)-2 and MMP-9 are associated with mortality during the acute phase of experimental Trypanosoma cruzi infection," Journal of Infectious Diseases, vol. 197, no. 10, pp. 1468-1476, 2008. 


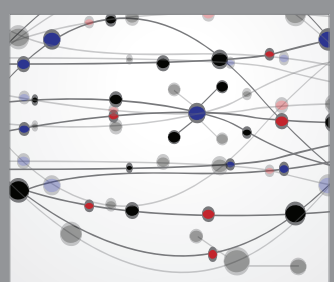

The Scientific World Journal
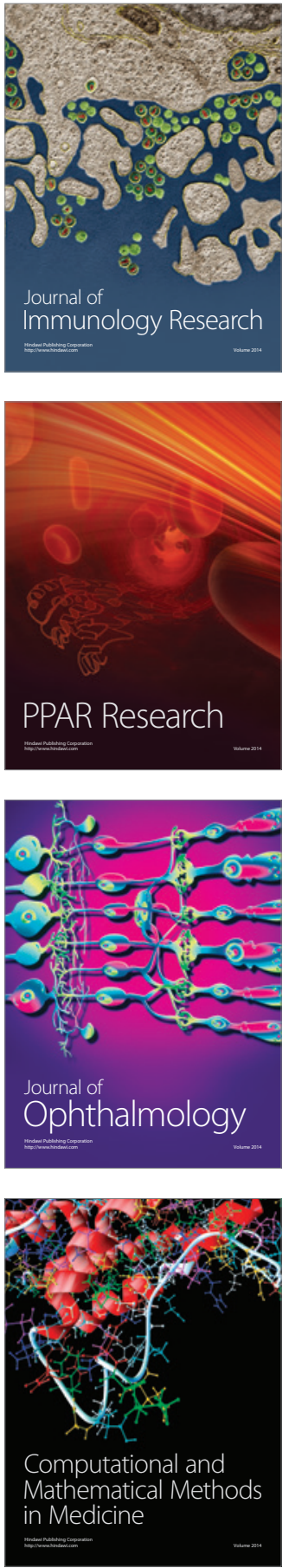

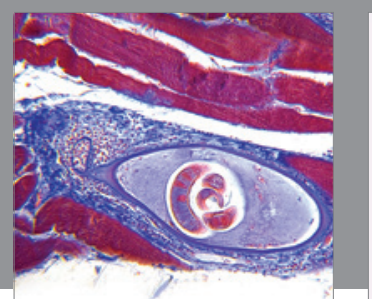

Gastroenterology Research and Practice

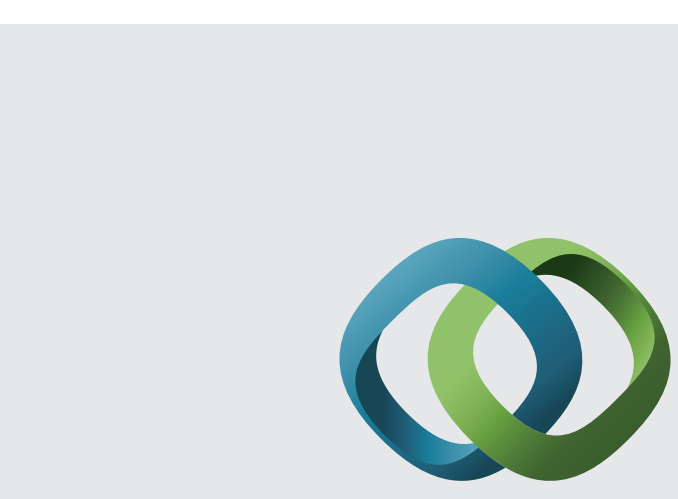

\section{Hindawi}

Submit your manuscripts at

http://www.hindawi.com
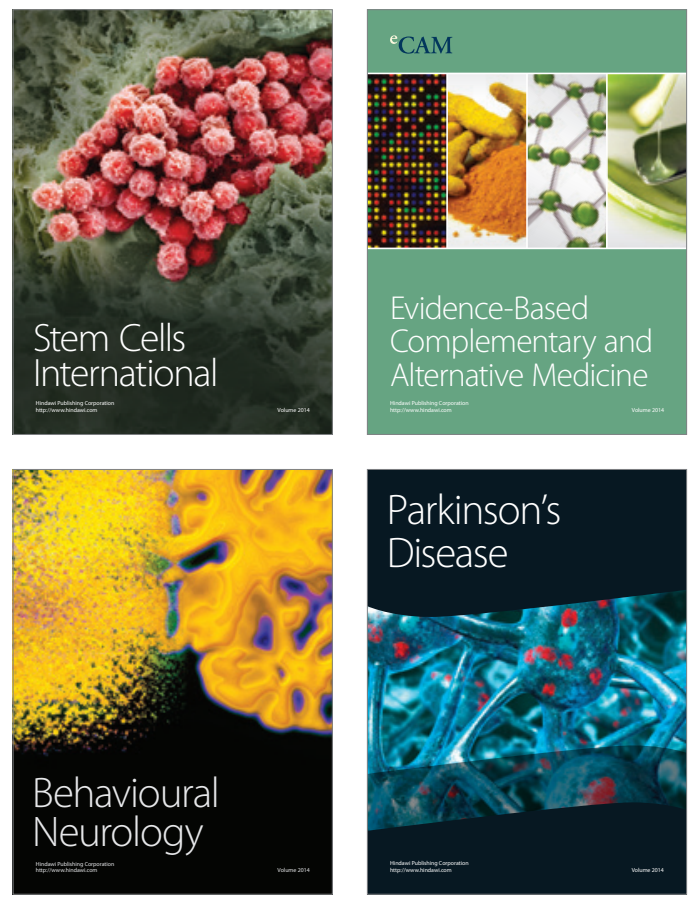
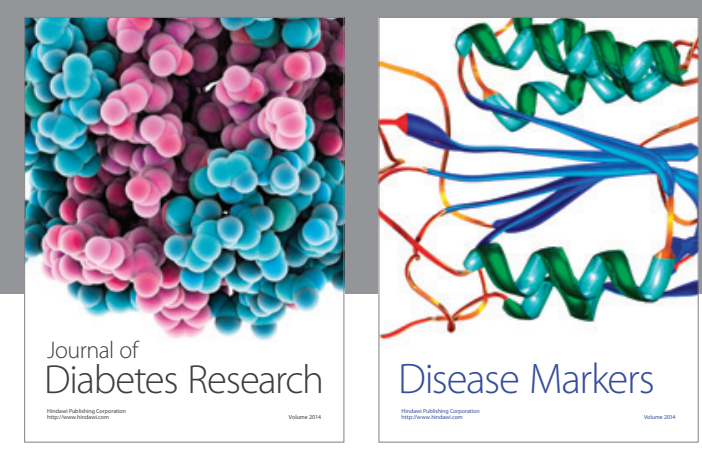

Disease Markers
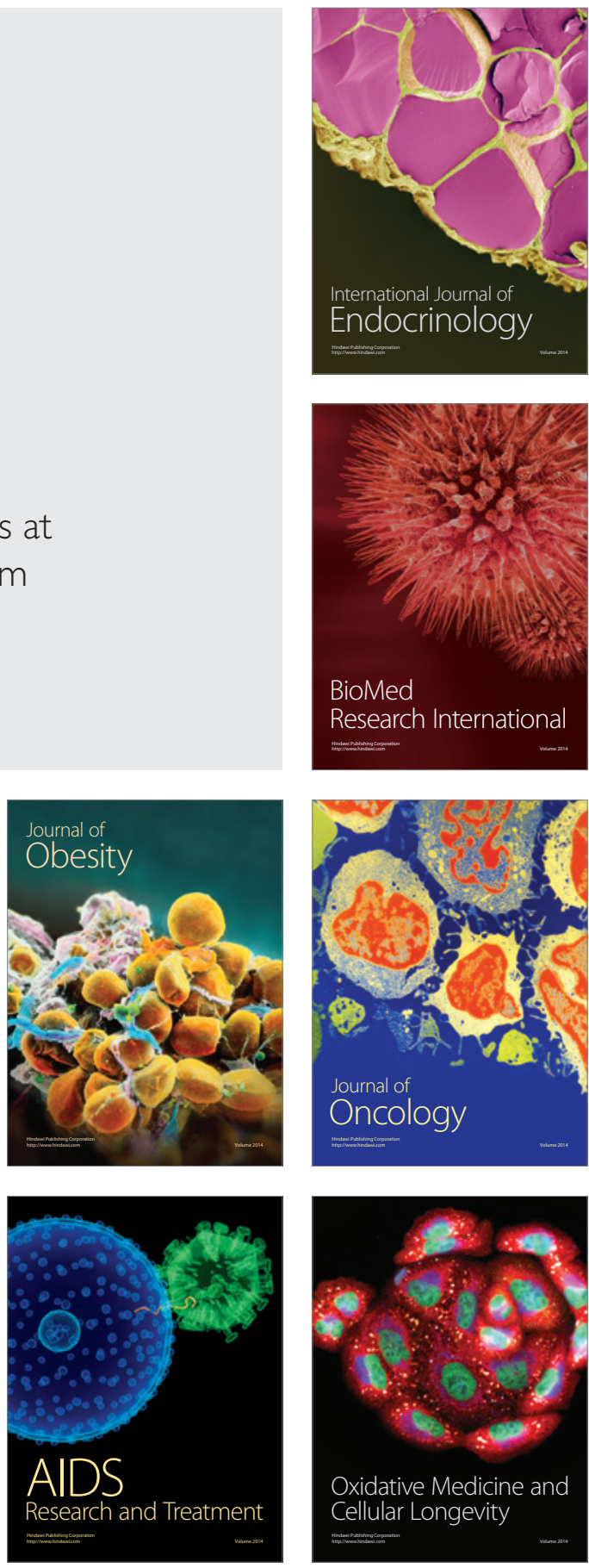